University of Nebraska - Lincoln

DigitalCommons@University of Nebraska - Lincoln

1995

\title{
Managing North American Waterfowl In The Face Of Uncertainty
}

James D. Nichols

Patuxent Environmental Science Center

Fred A. Johnson

Patuxent Environmental Science Center, fred_a_johnson@fws.gov

Byron K. Williams

University of Vermont

Follow this and additional works at: https://digitalcommons.unl.edu/usfwspubs

Nichols, James D.; Johnson, Fred A.; and Williams, Byron K., "Managing North American Waterfowl In The Face Of Uncertainty" (1995). US Fish \& Wildlife Publications. 373.

https://digitalcommons.unl.edu/usfwspubs/373

This Article is brought to you for free and open access by the US Fish \& Wildlife Service at DigitalCommons@University of Nebraska - Lincoln. It has been accepted for inclusion in US Fish \& Wildlife Publications by an authorized administrator of DigitalCommons@University of Nebraska - Lincoln. 


\title{
MANAGING NORTH
}

\section{AMERICAN WATERFOWL IN THE FACE OF UNCERTAINTY ${ }^{1}$}

\author{
James D. Nichols
}

National Biological Service, Patuxent Environmental Science Center, Laurel, Maryland 20708

\section{Fred A. Johnson}

Office of Migratory Bird Management, Patuxent Environmental Science Center, Laurel, Maryland 20708

\section{Byron K. Williams}

Vermont Cooperative Fish and Wildlife Research Unit, School of Natural Resources, University of Vermont, Burlington, Vermont 05405

KEY WORDS: waterfowl (Anatidae), hunting, adaptive management, population dynamics, North America

\begin{abstract}
Informed management of waterfowl (or any animal population) requires management goals and objectives, the ability to implement management actions, periodic information about population and goal-related variables, and knowledge of effects of management actions on population and goal-related variables. In North America, international treaties mandate a primary objective of protecting migratory bird populations, with a secondary objective of providing hunting opportunity in a manner compatible with such protection. Through the years, annual establishment of hunting regulations and acquisition and management of habitat have been the primary management actions taken by federal agencies. Various information-gathering programs were established and, by

${ }^{1}$ The US government has the right to retain a nonexclusive, royalty-free license in and to any copyright covering this paper.
\end{abstract}


the 1960s, had developed into arguably the best monitoring system in the world for continentally distributed animal populations. Retrospective analyses using estimates from this monitoring system have been used to investigate effects of management actions on waterfowl population and harvest dynamics, but key relationships are still characterized by uncertainty. We recommend actively adaptive management as an approach that can meet short-term harvest objectives, while reducing uncertainty and ensuring sustainable populations over the long-term.

\section{INTRODUCTION}

The term "waterfowl" refers collectively to members of the family Anatidaeducks, geese, and swans. Waterfowl have been referred to as "the most prominent and economically important group of migratory birds in North America" (24). The breeding distributions of the 45 species of waterfowl that are native breeders in North America range from the southern United States to Alaska and the Canadian arctic (7). As suggested by the term "waterfowl," wetlands are an essential habitat component for these species throughout their ranges. Most North American species are migratory, breeding in the northern United States and Canada during the spring and summer and migrating along traditional pathways to wintering grounds in the United States and, for some species, Mexico and even Central and South America. The prairies of northcentral United States and south-central Canada are an extremely important breeding area for many duck species, whereas many goose and swan species breed farther north in Alaska and the Canadian arctic.

Waterfowl hunting and associated management efforts have a long history in North America. This history has been closely linked with scientific investigations of waterfowl ecology that have guided waterfowl management over the years. Monitoring programs were established for the purpose of estimating key demographic parameters for waterfowl populations $(16,59,82)$, and biological understanding has been a cornerstone of many programs for the management of waterfowl habitats and the annual setting of waterfowl hunting regulations in North America. Few examples exist of a more successful longterm collaboration between wildlife research and management.

Despite this success, there remains substantial uncertainty about the effects of management on waterfowl populations. For example, waterfowl harvest management in North America continues to be limited by a less than complete understanding about the ecological relationships linking biological processes to harvest mortality $(3,64,67)$. Key relationships in the process of reproduction are yet to be fully understood, knowledge about the ecology of migration and patterns of movement is incomplete, and the role and 
importance of randomness in the environment awaits more comprehensive assessment.

This uncertainty extends to North American waterfowl populations and their sustainability (their ability to persist indefinitely, or at least into the forseeable future). The current health of North American waterfowl populations and their habitats varies from one species and location to another. Some arctic-nesting goose populations are increasing rapidly in abundance to the point where they are damaging habitat on the breeding grounds. Some duck populations have exhibited substantial declines, and breeding and wintering habitat for many duck species continues to be destroyed and degraded by agriculture and other human activities. Demands for high levels of sport harvest continue, and subsistence harvest (by indigenous peoples) is not well regulated or well monitored.

We believe that adaptive management $(39,41,88,89)$ offers the best approach to dealing with the various sources of uncertainty in future management efforts for North American waterfowl (50). In general terms, adaptive management involves (i) the choice of actions, taking into account uncertainty as to their consequences; (ii) monitoring and assessment of population dynamics; and (iii) use of the monitoring and assessment information in future decision-making. By this accounting, any management scenario that monitors the status of resources and tailors decisions accordingly can be described as adaptive. However, we use adaptive management more formally to represent a systematic process of using information generated by management actions to improve biological understanding and inform future decision-making. Passive and active forms of adaptive management are distinguished by the use of management actions to acquire useful information. In particular, we use the phrase adaptive waterfowl management in what follows to mean the active pursuit of information as an objective of the decision-making process. Thus delimited, adaptive waterfowl management can be described as an approach to dealing with the "dual control problem" of simultaneously pursuing harvest and conservation objectives on the one hand and the objective of improved understanding about population dynamics on the other (89).

Our purpose in this paper is first to review the history and evolution of waterfowl management in North America and then to describe the adaptive process that we propose for future management. We begin by presenting a conceptual basis for animal population management. We proceed to a brief historical review of the evolution of waterfowl management in North America, focusing on the close relationship between management approaches and ecological research on waterfowl populations. Following this review, we discuss some of the specific lessons learned from the North American experience and then conclude with a description of the proposed adaptive approach to waterfowl management. 


\section{CONCEPTUAL BASIS FOR ANIMAL POPULATION MANAGEMENT}

We believe that there are four fundamental requirements for the informed management of any animal population. First, the manager must develop explicit goals or objectives (e.g. these might involve harvest and population size). Second, the manager must have the ability to implement management actions that are relevant to the attainment of goals (e.g. actions might involve hunting regulations and protection/management of wetlands). Third, the manager must develop a program to gather information on important state variables (e.g. population size) and goal-related variables (e.g. harvest) for the managed population. Fourth, the manager must have a hypothesis or model about the effects of management actions on state and goal-related variables.

Given these four components, informed management can be implemented as an iterative process. Periodically, the information-gathering program provides an estimate of system state and goal-related variable(s). This information is used in conjunction with the model(s) of the harvested population to decide what management action is best with respect to the specified management objectives. Conceptually, the management of an animal population is a simple and straightforward process, but numerous problems typically arise as it is implemented.

\section{A SHORT HISTORY OF NORTH AMERICAN WATERFOWL MANAGEMENT}

The following review is abbreviated and selective. It reflects the bias of our own experiences, which have been in the United States and have emphasized ducks.

\section{Before 1930}

Prior to the mid-1800s waterfowl were extremely abundant in North America $(19,71,75)$, and hunting occurred throughout the year by both market and recreational hunters $(19,60,75)$. Waterfowl appear to have been perceived as an infinite natural resource, meriting no management intervention.

The late 1800s and early 1900 s were characterized by declining waterfowl numbers and the growing recognition that protection from excessive hunting and habitat loss was needed $(5,19,28,70)$. In the United States, the federal government was granted authority to implement management actions in the form of hunting regulations $(5,19,86)$ and land acquisition and protection $(31$, 77). The objective of such management, as stated in the Migratory Bird Treaty Act of 1918, was to protect migratory birds, and it was further specified that 
other objectives such as hunting would be permitted only to the extent that they were compatible with protection $(19,86)$.

Research on waterfowl distribution and migratory habits was begun $(5,12$, 19,31 ), but little information accrued on waterfowl abundance (annual estimates of system state) or about effects of management actions on waterfowl populations. The existing (albeit limited) knowledge of waterfowl abundance and population ecology led to the establishment of a closed season for all species during the primary breeding season as well as total protection from hunting for some species existing in very low numbers.

\section{$1930-1950$}

Waterfowl numbers were low during much of this period, and the US government carried out responsibilities under the Migratory Bird Treaty Act, primarily through acquisition and management of waterfowl habitat and annual setting of hunting regulations $(5,17,19,28,31)$. Decisions about the timing of the hunting season and where to purchase wetlands were aided by information on bird migration and distribution provided by waterfowl banding and winter survey data $(5,54,59,82)$. Winter survey data provided annual assessments of population status that were used in the development of hunting regulations (16), and band recovery data were used to provide indications of hunting intensity (53).

Regulations were restricted when populations were in decline $(63,86)$, indicating a clear effort to change management actions in response to changes in system state. There were no explicit models relating management actions to subsequent changes in population size. Instead, management actions were guided by the common-sense ideas that increased hunting mortality could lead to reductions in waterfowl abundance and that habitat acquisition and improvement could lead to increases in abundance.

\section{$1951-1975$}

From 1950-1975, the various data collection programs required to provide information for waterfowl management matured into probably the best such system for any continentally distributed animal population(s) in the world (59, 82 ). These programs reflect a productive collaboration between research and management and include: aerial breeding ground surveys (Figure 1) providing estimates of pond numbers, and estimates of adult population size and indices of brood numbers for prairie-nesting waterfowl species $(5,33,59)$; a harvest survey consisting of a mail questionnaire survey and a parts (duck wings and goose tails) collection survey, providing estimates of the waterfowl harvest by species, sex, and age $(5,10,58,59)$; an operational banding program, data from which are used to estimate harvest rates and annual survival rates $(9,36)$; 


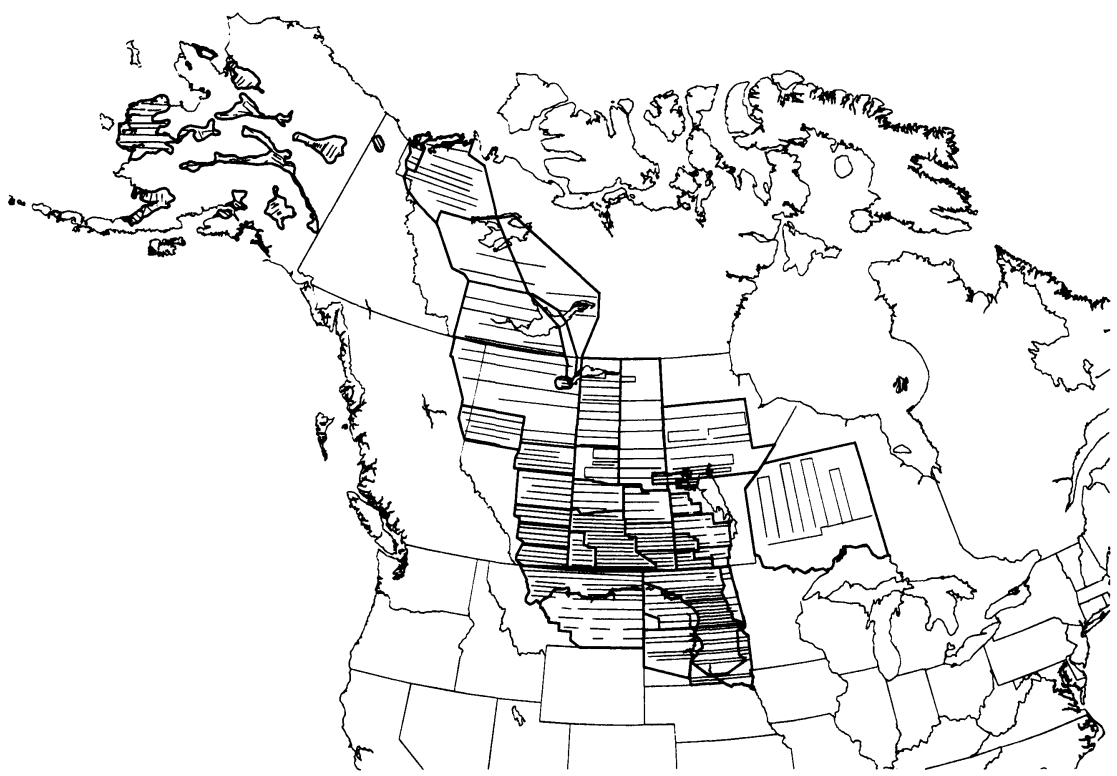

Figure 1 Strata and transects for the North American Waterfowl Breeding Population and Habitat Survey (59).

and a winter survey providing indices of waterfowl numbers and distribution on the wintering grounds $(59,82)$.

Research using data from these surveys found evidence of a strong positive relationship between May and July pond numbers on prairie breeding areas and fall age ratio of mallards (Anas platyrhynchos), permitting prediction of numbers of young mallards in the fall using aerial survey estimates of numbers of ponds in the spring and summer $(1,18)$. Field research provided evidence of the ability of specific land management practices to increase waterfowl reproductive rates $(6,20)$. Regression-based estimates of the positive, linear relationship between hunting and overall mortality of mallards (36) were used to predict the total mortality, and then the total population size, expected to result from imposition of hunting regulations leading to specific band recovery rates (29).

Prior to this period, band recovery and survey data had led to the conclusion (54) that North American waterfowl followed four major flyways (migration paths and their associated wintering grounds; Figure 2). A flyway council system based on these geographic units was developed whereby state and federal (US, Canadian, Mexican) representatives were given a major role in 


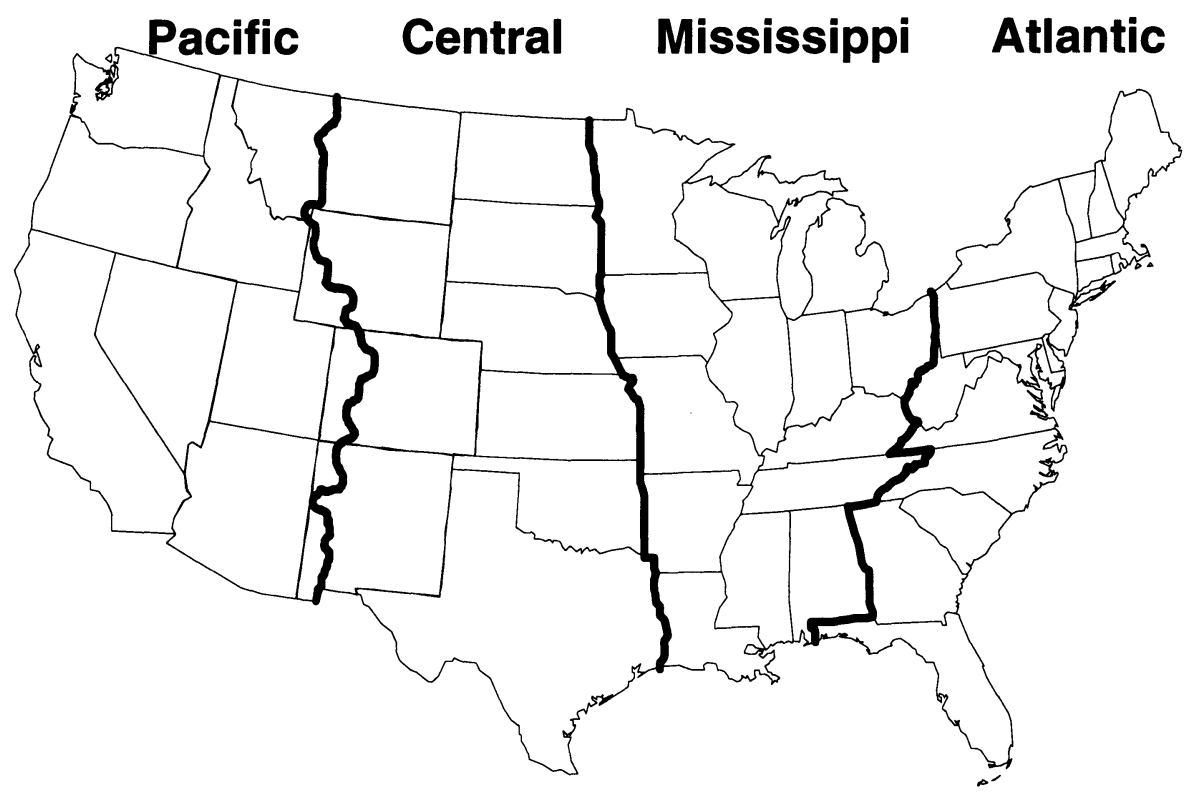

Figure 2 Administrative waterfowl flyways in the United States (5).

the coordination of flyway-specific management activities, including development of annual hunting regulations (43). The establishment of the flyway councils was accompanied by an increase in the complexity and geographic variation of hunting regulations $(63,86)$.

Some important waterfowl populations exhibited substantial fluctuations during this period. Each summer, waterfowl managers and researchers considered current population sizes and habitat conditions, together with the dual goals of hunting opportunity and healthy waterfowl populations, and developed a desired population size for the following spring. Population models were used to derive specific numerical harvest objectives termed "harvestable surplus" (16) or "allowable harvest" (29). Band recovery data were used to estimate the direct effect of hunting on waterfowl mortality and thus on waterfowl population dynamics $(29,36)$. Armed with objectives, timely information about system state, and estimated effects of management on system state, North American waterfowl managers varied regulations in direct response to population fluctuations. Indeed, except for the disagreements among different interest groups about population goals, waterfowl management in North America during the 1960 s and early 1970 s was viewed as an ideal example of scientific management of animal populations. 


\section{$1976-1993$}

During the early 1970s, researchers recognized that previous methods for estimating annual survival rates from waterfowl band recovery data required very unrealistic assumptions, so they developed more reasonable estimation methods $(9,79,80)$. More importantly, previous inferences about the positive, linear relationship between hunting and overall mortality rate (the "additive" mortality hypothesis) were shown by Anderson \& Burnham (3) to be an inevitable consequence of sampling covariation between estimators; they thus destroyed all evidence of this relationship. New tests of the relationship between hunting and overall mortality for mallards, using reasonable statistical approaches, supported the "compensatory" mortality hypothesis, that for a certain range of hunting mortality rates, changes in hunting mortality were compensated by changes in nonhunting mortality such that overall mortality remained unchanged (3). Subsequent retrospective analyses of data from North American ducks have provided a mixture of inferences about the effects of hunting on overall mortality and population dynamics $(64,67,86)$, whereas the few studies of geese have supported the additive mortality hypothesis (26, $34,76)$.

The relationship between hunting and overall mortality rates is central to reasonable management, and the two extreme hypotheses describing this relationship (completely compensatory, completely additive) lead to very different management strategies $(2,92)$. The results of initial analyses supporting the compensatory mortality hypothesis (3) led to relatively liberal hunting regulations during the late 1970 s. Regulations were experimentally stabilized in both the United States and Canada during 1979-1984 (83) at relatively liberal levels in an effort to investigate effects of environmental variation on population parameters. Duck populations were generally low during the 1980s (Figure 3), and regulations following the stabilized period were restrictive, reflecting a "risk-aversive conservatism" in the face of uncertainty about effects of hunting on waterfowl populations (86).

Research on the relationship between hunting mortality rate and the various components of hunting regulations led to the conclusion that major changes in regulations produced the intended changes in waterfowl harvest rates, but that there was little evidence of the effectiveness of so-called special regulations designed to fine-tune harvest management $(64,68)$. Continued research on the relationship between habitat management and waterfowl population dynamics $(21,22)$ led to the development of explicit models relating different types of habitat management to mallard reproductive rates (and hence population status) in prairie breeding areas of the United States $(14,15,49)$.

In response to concern over low populations of several important duck species and continuing high rates of wetland habitat loss and degradation, 


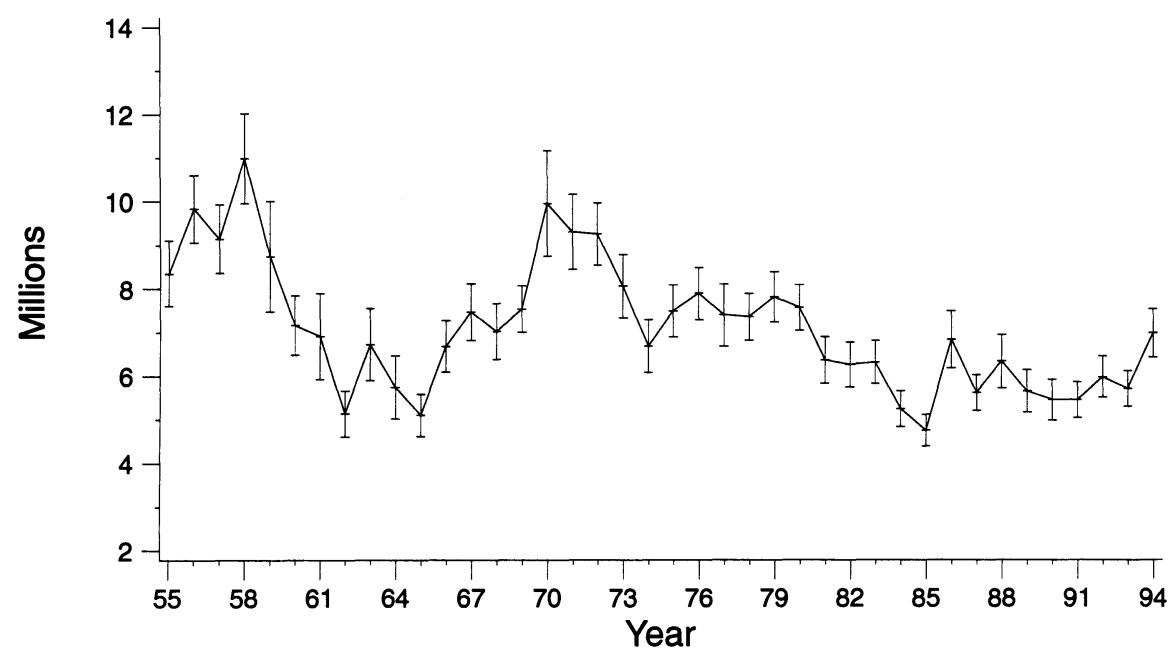

Figure 3 Breeding population estimates and 95\% confidence limits for mallards in North America.

representatives of Environment Canada and the US Department of the Interior signed the North American Waterfowl Management Plan in 1986 (24). This document reflects the recognition that recovery and perpetuation of North American waterfowl populations depend on restoring wetlands and their associated ecosystems throughout the continent. The Plan lists explicit habitat objectives and numerical population goals for many waterfowl species $(24$, 87).

The last two decades have been characterized by low populations of several duck species, by large and increasing populations of several goose species, and by uncertainty about effects of management actions. Research results continued to influence management decisions, and the inconclusive nature of many such results was a major source of management uncertainty. During this period, management goals were periodically presented, and the data collection programs continued to provide useful information about waterfowl population status. The importance of quality habitat to waterfowl populations was generally accepted, as reflected in the North American Waterfowl Management Plan.

\section{LESSONS LEARNED}

We believe that waterfowl management in North America has been successful in many respects. Most waterfowl populations remain healthy, millions of hectares of habitat have been purchased or are under conservation easement, 
and sport harvest is carefully monitored and regulated. A number of important reasons explain this success: Various pieces of legislation vested management jurisdiction with federal governments and curtailed commercial hunting; treaties provided for international cooperation in migratory bird management; funding mechanisms, including the sale of hunting permits, facilitated the purchase and management of important habitats; large-scale monitoring and research programs were implemented, and for the most part, harvest levels were conservative.

Our overall positive assessment notwithstanding, we believe that substantial room for improvement exists in North American waterfowl management. In the following discussion we point to some of the lessons that emerge from our examination of the history of waterfowl management in North America in hopes that they may be useful in our future management efforts to ensure sustainable waterfowl populations. We have organized this discussion into two general categories: (i) management objectives and the process of making decisions, and (ii) the relationship between management actions and population status.

\section{Management Objectives and Decision-Making}

The treaties between the United States and Canada and the United States and Mexico provide only a broad mandate for migratory bird conservation. The establishment of specific management objectives is the responsibility of those federal, state, and provincial agencies vested with management authority. The mandated objectives of federal waterfowl management are clear in specifying protection and conservation of migratory bird populations first and sport hunting second. However, the existence of dual, potentially antagonistic, objectives leaves much room for discussion and argument.

For example, in years of favorable habitat conditions, there will typically be many different sets of hunting regulations (and resultant harvest rates) that permit sport harvest and that should also result in population growth. Complete specification of this management problem requires the assignment of "weights" reflecting the relative importance of the population and harvest objectives. The flyway council system permits input to decisions about hunting regulations from federal and state government agencies and from private organizations ranging from private hunting groups to strict protectionist organizations. We believe that much of the controversy that has arisen in the development of duck hunting regulations over the years has resulted from the different relative weights or values placed on these two objectives by various agencies and interest groups.

We believe further progress in waterfowl management will require clearly stated objectives that identify measurable responses. We fully appreciate that development of explicit objectives will be extremely difficult. However, in the 
absence of explicit objectives, it is not possible objectively to compare alternative management choices or to gauge management performance. Objectives also help define and bound the extent of the ecological, social, and economic models that are necessary for evaluating alternative management strategies. Ultimately, consensus on specific objectives may not be possible, but managers will nonetheless benefit from a better understanding of the nature and breadth of the desires of the various resource-user groups.

The operational aspects of decision-making in waterfowl management, particularly those involving harvest regulation, have been well documented ( 8 , $17,28,29,85)$. Currently, regulations governing sport harvest are promulgated annually in Canada, the United States, and Mexico in an elaborate process that is designed to elicit input from state, provincial, and federal conservation agencies. No such formal process exists for decisions regarding habitat management, although joint ventures under the North American Waterfowl Management Plan provide some opportunity for review and coordination of activities. Rather than discuss the details of these processes, we believe it is more instructive to focus on the conceptual aspects of making waterfowl management decisions.

Both science and management make use of statistical inference, but the different objectives of these two endeavors may lead to different statistical perspectives and approaches. One such difference in perspective is related to the treatment of Type I and II error rates. In science there is a strong bias against Type I errors, in which a null hypothesis (the hypothesis of no difference) is mistakenly rejected. Thus, the investigator typically assigns a low probability (e.g. 0.05) for Type I errors, despite the fact that lower probabilities of Type I errors produce higher probabilities for Type II errors (failures to reject false null hypotheses and, hence, to detect real differences). This tendency, when applied in waterfowl harvest management, has sometimes placed the burden of proof on those charged with resource maintenance, rather than on those seeking higher levels of exploitation $(67,86)$. In many instances, we probably should be more concerned with Type II errors, where a real response to management or the environment goes undetected. We should assess risks associated with the two types of errors and establish error rates accordingly, rather than relying on the traditional error rates used in the scientific literature (37).

Decision-making in the face of uncertainty implies risk, and we should make efforts to evaluate the risks associated with alternative decisions. Although management at the federal level has focused on the risk of declines in waterfowl abundance, such management has not dealt with risk in a consistent manner. Perhaps the greatest need for the sustainable management of waterfowl, as with other renewable resources, is a strategic plan for coping with the inherent uncertainty and risk in the decision-making process $(38,88)$. Methods 
of Bayesian inference and decision may be helpful in addressing this and other problems faced by waterfowl managers $(42,96)$.

\section{Investigating and Modeling the Relationship Between Management Actions and Population Status}

In our earlier outline of the conceptual basis for management, we specified the need for two kinds of information: (i) periodic information about variables related to both the state of the managed system (e.g. population size) and management goals (e.g. number of birds harvested), and (ii) information about the relationship between management actions and population status. The datacollection programs implemented for North American waterfowl populations $(5,17,59,82)$ meet the first need.

In response to the second information need, we have often estimated key relationships using retrospective studies that compute measures of association between historical changes in relevant demographic variables and management actions (66). These studies lack replication and random assignment of treatments to experimental units, two of the key features of manipulative experimentation (25). Inferences from these retrospective studies are thus weak, admitting alternative explanations for observed changes in population response variables $(64-66,68)$.

Some characteristics of waterfowl harvest management in North America have been especially detrimental to efforts to understand effects of management actions through retrospective analyses. For example, our ability to draw inferences from retrospective studies has been limited by the historical tendency to manage for population stability by liberalizing hunting regulations when waterfowl were abundant and restricting regulations when waterfowl populations were low $(50,67)$. This harvest strategy has produced a large-scale confounding of environmental, density-dependent, and harvest effects (Figure 4). We agree with the many investigators who have recommended either experimental hunting seasons or an adaptive management approach as means of drawing stronger inferences $(3,4,50,64-68,95)$.

In many cases, the sheer number and complexity of management actions has overwhelmed managers' abilities to evaluate their effects (68). Complexity of hunting regulations (86) has contributed greatly to uncertainty about management effects, while it is not clear that it has increased hunter satisfaction. We recommend restricting the number of management options to a relatively small number of very different alternatives, because the costs of learning about the effects of many small, "fine-tuning" changes in regulations likely would be prohibitive, especially when viewed in the context of the relatively small gains that might arise from their use (68).

Both the implementation of management decisions regarding migratory birds and the evaluation of effects of these actions are made more difficult by 


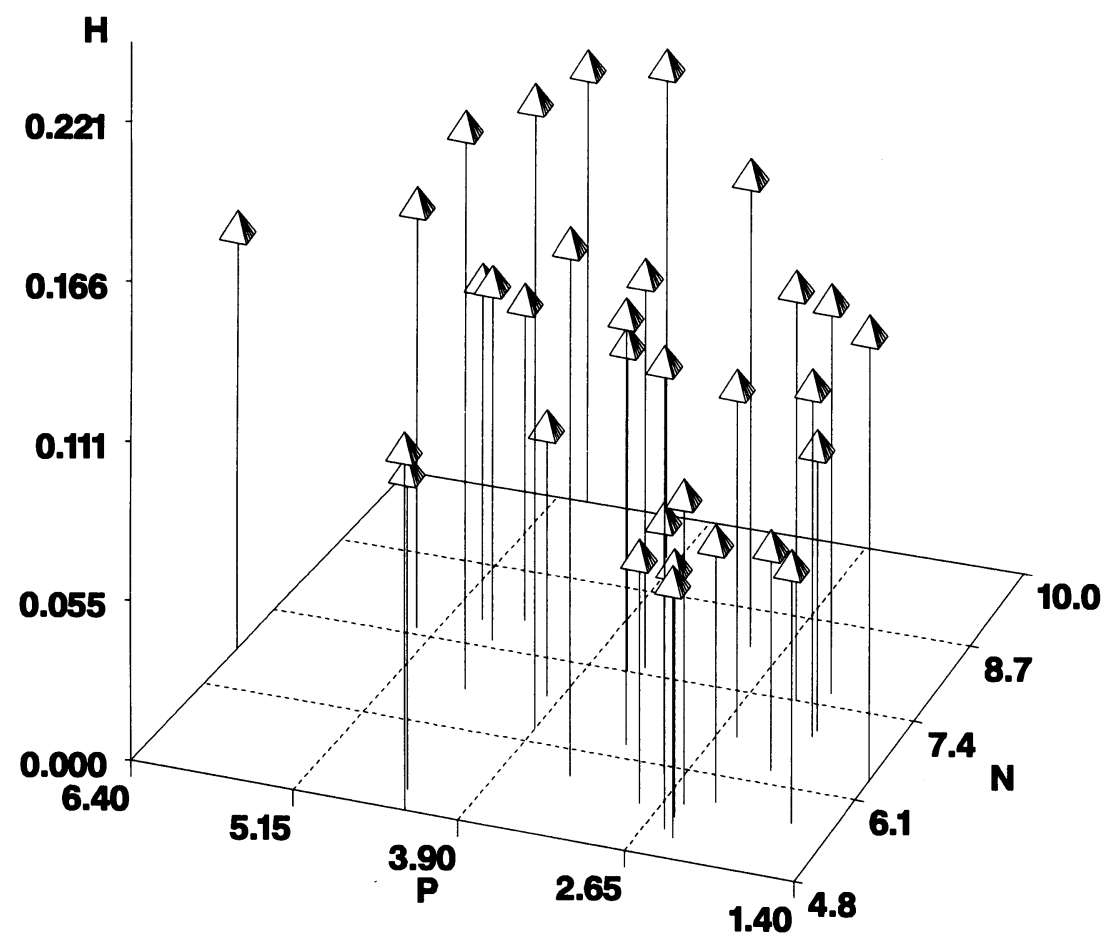

Figure 4 Harvest rates $(H)$ of adult male mallards in relation to population size ( $N$, in millions) and pond numbers $(P$, in millions) in Prairie Canada.

problems of geographic scale. Waterfowl populations rarely form discrete units, and heterogeneity among populations sharing study area can make inference about management effects difficult $(44,46)$. We recommend that experimentation or adaptive management consider scale problems in the implementation of different management treatments, trying to direct studied management actions at specific groups of birds, to the extent possible.

In addition to key relationships that have received (usually retrospective) study, some important relationships have received little study under any approach, and these merit additional attention. Possible density-dependence of reproductive $(1,23,47,51)$ and survival $(1,3,47,64,67)$ rates in duck populations has received insufficient attention, despite its pivotal importance in defining population responses to management.

Decisions about habitat acquisition and management require information about the relationship between habitat characteristics and waterfowl survival and reproduction. Some investigations of the relationship between specific 
habitat characteristics and components of reproductive rate have been completed $(20,21,47)$, and results have been incorporated in population modeling efforts $(13,14,15,49)$. The relationship between habitat and survival probability, however, has not been well-studied.

We have devoted inadequate attention to functional relationships involving humans (57), such as the relationship between hunting regulations and hunter participation and the positive influence of hunter numbers on waterfowl population status through provision of funds for habitat acquisition and management. Miller \& Hay (61) and Hochbaum \& Walters (40) provide good examples of considering waterfowl hunters in modeling efforts.

Our "knowledge" of effects of management actions on waterfowl populations can be encoded in models, and these models can then be used to consider consequences of alternative actions. Uncertainty associated with these models translates directly into uncertainty about the appropriateness of management decisions. We believe that the degree of uncertainty about management effects has strongly influenced the degree to which explicit population models have been used to guide waterfowl management during the last three decades. During the 1960s, when the relationship between hunting regulations and population status was believed to be known with high certainty, explicit population models played an important role in management decisions (29). Results of Anderson \& Burnham (3) did not support these models, and explicit population models have seen only limited use in guiding harvest management actions during the last two decades (95).

Although uncertainty of key functional relationships is a legitimate and important problem, we do not believe that it should be used as a rationale for not engaging in model development and use. We believe that explicit models are important in providing a clear basis for management decisions and making predictions that can be used as the basis for future learning.

We believe that mechanistic models may make better choices for management applications than are phenomenological models (empirical models that simply describe an observed statistical relationship, without reference to the mechanism responsible for the relationship). Mechanistic models have a greater probability of providing accurate predictions outside the range of conditions experienced during model development. This conclusion emerges from a consideration of model forms that characterize the relationship between harvest rate and annual survival rate (50).

We also believe that models incorporating spatial dynamics of waterfowl populations will become increasingly important as issues of population distribution and harvest allocation come to the forefront in discussions of waterfowl management objectives. Some work has been completed on estimating area-specific rates of survival and movement for waterfowl $(35,78)$ and on incorporating such estimates into population models describing spatial dynamics $(52,90)$. 
Finally, we repeat the recommendation of Conroy (11) that models subjected to few or no validation efforts should not be used unquestioned as the basis for management decisions. Uncertainty about key relationships leads us to advocate the approach of considering multiple models (rather than a single most-probable model) in the development of management strategies and then assessing relative credibility by comparing competing predictions with subsequent observations.

\section{MANAGING IN THE FACE OF UNCERTAINTY}

\section{Components of Uncertainty in Waterfowl Management}

There are at least four identifiable attributes of waterfowl biology that generate uncertainty and motivate the need to account for uncertainty in waterfowl management. We identify these sources of uncertainty using the terminology of operations research and decision theory in order to emphasize that the specific problems of waterfowl management fall within a broad class of problems associated with management of stochastic systems.

The first source of uncertainty is uncontrollable (and possibly unrecognized) environmental variation, which influences biological processes and induces stochasticity in population dynamics $(1,2,16,18,19,29,47,66,71,72)$. For example, weather variables and habitat conditions on breeding and wintering grounds can influence reproductive rates $(1,2,18,30,32,47,51,72,74)$, survival rates (47), and migration and distribution patterns $(45,69)$.

The second source of uncertainty is limited knowledge about underlying biological mechanisms and about relationships between management actions and population status, identified in what follows as structural uncertainty. An example is the management of waterfowl harvests, for which there is a substantial lack of agreement as to which hypothesis (i.e. "additive" or "compensatory") best describes the relationship between harvest rate and annual survival rate $(3,64,67)$. Because of the cost associated with such uncertainty (50), it is important to seek its elimination as a management goal, along with other traditional harvest goals.

Uncertainty about population status, referred to as partial observability, reflects imprecision in the monitoring of a biological system. Such uncertainty imposes limits on harvest management, even if one understands with certainty the underlying biological mechanisms and has total control over harvest rates. Partial observability limits the ability to recognize the need for protection, or to respond to utilization opportunities when they occur.

Partial controllability expresses the fact that management decisions only partially control the actual magnitude of the corresponding action [e.g. harvest regulations control actual harvest rates (and harvest effects) only within certain 
limits of precision]. The inability to specify harvest rates accurately can limit both short-term management performance and the reduction of structural uncertainty, irrespective of monitoring precision.

The uncertainty factors listed above are operative on any biotic resource subject to management. Indeed, in recent years, management of renewable resources has increasingly recognized the need to account for uncertainty $(39$, $62,88,93)$. It is most fortunate that by now a powerful statistical and mathematical theory is available for the treatment of uncertainty in dynamic systems (84), and computer software is being developed for assessment of uncertain systems $(55,56,94)$.

\section{A Systematic Approach to Adaptive Waterfowl Management}

Adaptive management was defined in the Introduction. A technical specification of adaptive waterfowl management involves the following components:

MANAGEMENT OPTIONS An array of potential management actions must be available for decision-making at each decision point in some relevant time frame. For example, adaptive harvest management might include a range of potential regulations from "restrictive" to "liberal", with the proviso that (i) the regulations represent realistic alternatives, and (ii) they include enough variation to elicit differential population responses. We use $a_{t}$ to represent the management action in year $t$, and $A$ to represent a sequence $\left\{a_{1}, \ldots, a_{T}\right\}$ of actions over a time frame $T$. The sequence $A$, sometimes called a management strategy or policy (91), might consist of a series of decisions about land management on wildlife refuges, along with the annual setting of harvest regulations. The management of waterfowl ultimately consists of policy choices in accordance with management objectives, recognizing that the action specified at a particular time should be tailored to population and habitat conditions.

MODEL SET An adaptive approach recognizes a collection of alternative biological mechanisms for population dynamics, with uncertainty as to which is most appropriate for the population under consideration. These are represented by dynamic population models, each model predicting population responses to management as functions of initial population status, environmental conditions, and management actions. Population dynamics are expressed by

$$
N_{t+1}=N_{t}+G_{i}\left(N_{t}, a_{t}, \underline{e}_{t}, \underline{z}_{t}\right)
$$

for model $m_{i}$, where $\underline{e}_{t}$ are time-varying environmental or habitat conditions, the random variable $\underline{z}_{t}$ represents a white noise process, and $G_{i}\left(N_{t}, a_{t}, \underline{e}_{-}, \underline{z}_{t}\right)$ is 
the net population growth from $t$ to $t+1$. It sometimes is useful to express environmental or habitat conditions similarly,

$$
\underline{e}_{t+1}=\underline{e}_{t}+\underline{E}_{i}\left(\underline{e}_{t}, a_{t}, \underline{z}_{t}\right) \text {, }
$$

and a generic representation includes both population and environmental state variables in a single-state transition equation:

$$
\underline{x}_{t+1}=\underline{x}_{t}+\underline{F}_{i}\left(\underline{x}_{t}, a_{t}, \underline{z}_{t}\right) \text {, }
$$

recognizing that $a_{t}$ can influence either population status or habitat conditions or both.

MONITORING PROGRAM To assess the state of the system and to gauge model performance in tracking population dynamics, some level of population monitoring is required. Let $\psi_{t}$ represent data that are recorded about the population at time $t$, with the value $\psi_{t}$ stochastically dependent on the system state $x_{t}$ :

$$
\underline{y}_{t}=g\left(x_{t}\right)+\underline{\varepsilon}_{t},
$$

and with the random variable $\varepsilon_{t}$ independent of $z_{t}$. Monitoring data accumulate through time, and each year additional data are added to an extant database $Y_{i}$ :

$$
Y_{t+1}=\left\{Y_{t}, y_{t+1}\right\} .
$$

In general, the more sophisticated and precise the program for monitoring population status (i.e. the smaller the variances in $\varepsilon_{t}$ ), the easier it is to resolve uncertainties about biological mechanisms and thus improve the management of waterfowl.

MEASURES OF UNCERTAINTY Key to an adaptive approach is the tracking of the confidence (or equivalently, the uncertainty) associated with each population model under consideration. Here we use $p_{i}(t)$ to represent the likelihood at time $t$ that model $m_{i}$ is the most appropriate for describing population dynamics. This notation indicates that the likelihoods vary among models, and the likelihoods change through time as the population responds to management actions. Variation in the likelihood values through time is based on the comparison of monitoring data and model predictions and therefore is informed by monitoring data: $p_{i}(t)=p\left(m_{i} \mid Y_{t}\right)$.

OBJECTIVE FUNCTION An objective function is a formal expression of management objectives and is needed to compare and evaluate different management policies. The function provides a measure of the effect of different management policies and thereby permits identification of optimal policies. For example, a useful objective function for harvest regulation might include the total predicted harvest over the timeframe, as influenced by regulatory 
strategies and model likelihood values. An objective function for habitat management might include both resource benefits and possible management costs. We use $\left.V(A\} Y_{0,20}\right)$ to denote the value of the objective function, conditional on accumulated monitoring information and current likelihood values. For example, an objective based on total accumulated harvest might be:

$$
\underline{V}\left(\underline{A} \mid Y_{0}, p_{0}\right)=\sum_{i} p_{0}(i) E\left(\sum_{i=0}^{T}\left[H_{i}\left(N_{t}, a_{t}\right) \mid Y_{0}\right]\right),
$$

with $E\left[\Sigma_{l} H_{i}\left(N_{t}, \mathrm{a}_{t}\right) \mid Y_{0}\right]$ the total expected harvest for model $m_{i}$, given the current data $Y_{0}$ and action $a_{t}$ at time $t$.

With these components, the adaptive management of waterfowl can be expressed in terms of dynamic optimization. Thus, waterfowl managers seek a policy $\underline{A}$ over the timeframe $\underline{T}$ that maximizes $V\left(\underline{A} \mid Y_{0}, \underline{p}_{0}\right)$ subject to:

$$
\begin{aligned}
& \underline{x}_{t+1}=\underline{x}_{t}+\underline{F}_{i}\left(x_{t}, a_{t}, \underline{z}_{t}\right) \\
& \underline{y}_{t+1}=\underline{g}\left(\underline{x}_{t}\right)+\underline{\varepsilon}_{t},
\end{aligned}
$$

recognizingthatparticular actions $a_{t}$ in $\underline{A}$ at each point in time are dependent onaccumulated monitoringinfor mationand themodellikelihoodsat thattime.

Expressing the adaptive management problem in this way allows us to use the theor $y$ and methods of dynamicestimation and optimization (84), particularly the procedures for analysis of Markov decision processes $(73,94)$.

\section{Advantages and Limitations in Managing Waterfowl Adaptively}

An important advantage to using an adaptive approach to dealing with uncertainty in waterfowl management is that it requires making explicit the factors entering into the decision-making process, thus reducing ambiguities. Other advantages accrue because of the dynamic nature of an adaptive approach, with an accounting for population changes through time and for future consequences of present actions. A dynamic framework involving an extended management timeframe requires of management that it be future-oriented, balancing the current benefits of resource use against future benefits accruing to resource conservation and sustainability. Another benefit of an adaptive approach is that it establishes a framework to include nonsportsmen and others with strong conservation interests, without excluding those who engage in the sport hunting of warterfowl. Finally, adaptive management provides a framework in which managers and researchers can work cooperatively on issues that are important to each group. Value is ascribed to information and understanding to the extent that they contribute to the goals of resource management, so that biological monitoring, assessment, and research are recognized as contributing to improved management. 
Recognizing the many advantages of an adaptive approach to waterfowl management, it also is useful to recognize that there are some potentially important limitations as well. One such concern involves identification of the models to be used (50). It is not likely that management can be informative of population dynamics, if the models under consideration are inadequate. But the recognition of, and agreement on, reasonable candidate models can be problematic and likely require considerable effort, creativity, and goodwill among stakeholders. Biological relationships controlling population dynamics also can change through time. If the rate of change in key relationships is similar to the rate of learning through adaptive management, then learning essentially becomes impossible. The potential for this problem is real. For example, evidence from banding assessments suggests compensatory patterns of hunting mortality for mallards in the 1970s (3), but additive effects in the 1980s (81). Despite this potential limitation, adaptive management should still be preferable to static approaches to management when key biological relationships change over time. Beyond these technical problems, full implementation of adaptive waterfowl management requires agreement among stakeholders about objectives, constraints, model sets, and management options, as well as an institutional environment conducive to objective management. The necessary cooperation among groups can be developed only through participation and interaction. We are hopeful that such cooperation will be achieved and believe that adaptive management provides a framework for rational waterfowl management that meets the needs for change and offers an excellent opportunity to achieve sustainability.

Any Annual Review chapter, as well as any article cited in an Annual Review chapter, may be purchased from the Annual Reviews Preprints and Reprints service. 1-800-347-8007; 415-259-5017; email: arpr@class.org

\section{Literature Cited}

1. Anderson DR. 1975. Population ecology of the mallard. V. Temporal and geographic estimates of survival, recovery, and harvest rates. US Fish Wildl. Serv. Res. Publ. 125. 110 pp.

2. Anderson DR. 1975. Optimal exploitation strategies for an animal population in a Markovian environment: a theory and an example. Ecology 56: 1281-97

3. Anderson DR, Burnham KP. 1976. Population ecology of the mallard. VI. The effect of exploitation on survival. US Fish Wildl. Serv. Res. Publ. 128. $66 \mathrm{pp}$.

4. Anderson DR, Burnham KP, Nichols JD, Conroy MJ. 1987. The need for experiments to understand population dynamics of American black ducks. Wildl. Soc. Bull. 15:282-84

5. Anderson DR, Henny CJ. 1972. Population ecology of the mallard. I. A review of previous studies and the distribution and migration from breeding areas. US Fish Wildl. Serv. Res. Publ. 105. $166 \mathrm{pp}$.

6. Balser DS, Dill HH, Nelson HK. 1968. Effect of predator reduction on waterfowl nesting success. J. Wildl. Manage. 32:669-82

7. Bellrose FC. 1976. Ducks, Geese \& Swans of North America. Harrisburg, PA: Stackpole. 543 pp.

8. Blohm RJ. 1989. Introduction to har- 
vest-understanding surveys and season setting. Proc. Int. Waterfowl Symp. 6: 118-33

9. Brownie C, Anderson DR, Burnham KP, Robson DS. 1978. Statistical inference from band recovery data: a handbook. US Fish Wildl. Serv. Res. Publ. 130. $212 \mathrm{pp}$.

10. Carney SM. 1992. Species, Age and Sex Identification of Ducks Using Wing Plumage. Washington DC: US Fish Wildl. Serv. 144 pp.

11. Conroy MJ. 1993. The use of models in natural resource management: prediction, not prescription. Trans. N. Am. Wildl. Nat. Res. Conf. 58:509-19

12. Cooke WW. 1906. Distribution and migration of North American ducks, geese, and swans. USDA Biol. Surv. Bull. 26. 90 pp.

13. Cowardin LM, Johnson DH. 1979. Mathematics and mallard management. J. Wildl. Manage. 43:18-35

14. Cowardin LM, Johnson DH, Frank AM, Klett AT. 1983. Simulating results of management actions on mallard production. Trans. N. Am. Wildl. Nat. Res. Conf. 48:257-72

15. Cowardin LM, Johnson DH, Shaffer TL, Sparling DW. 1988. Applications of a simulation model to decisions in mallard management. US Fish Wildl. Serv. Tech. Rep. No. 17. 28 pp.

16. Crissey WF. 1957. Forecasting waterfowl harvest by flyways. Trans. $N$. Am. Wildl. Conf. 22:256-68

17. Crissey WF. 1963. Exploitation of migratory waterfowl populations in North America. In Proc. European Meeting on Wildfowl Conservation, 1st, St. Andrews, Scotland, pp. 105-22. London: Nature Conservancy

18. Crissey WF. 1969. Prairie potholes from a continental viewpoint. Saskatoon Wetlands Seminar. Can. Wildl. Serv. Rep. Ser. 6:161-71

19. Day AM. 1949. North American Waterfowl. Harrisburg, PA: Stackpole. 329 pp.

20. Duebbert HF, Kantrud HA. 1974. Upland duck nesting related to land use and predator reduction. J. Wildl. Manage. 38:257-65

21. Duebbert HF, Lokemoen JT. 1976. Duck nesting in fields of undisturbed grass-legume cover. J. Wildl. Manage. 40:39-49

22. Duebbert HF, Lokemoen JT. 1980. High duck nesting success in a predator-reduced environment. J. Wildl. Manage. 44:428-37

23. Dzubin A. 1969. Comments on carrying capacity of small ponds for ducks and possible effects of density on mallard production. Saskatoon Wetlands Seminar. Can. Wildl. Serv. Rep. Ser. 6:13860

24. Environment Canada and US Department of the Interior. 1986. North American Waterfowl Management Plan. Washington, DC: US Fish Wildl. Serv. 19 pp.

25. Fisher RA. 1971. The Design of Experiments. New York: Hafner. 248 pp.

26. Francis CM, Richards $\mathrm{MH}$, Cooke F, Rockwell RF. 1992. Long-term changes in survival rates of lesser snow geese. Ecology 73:1346-62

27. Deleted in proof.

28. Gabrielson IN. 1941. What is behind the waterfowl regulations. Report of the Special Senate Committee on the Conservation of Wildlife Resources, 77th Congress. Washington, DC. 34 pp.

29. Geis AD, Martinson RK, Anderson DR. 1969. Establishing hunting regulations and allowable harvest of mallards in the United States. J. Wildl. Manage. 33: 848-59

30. Hammond MC, Johnson DH. 1984. Effects of weather on breeding ducks in North Dakota. US Fish Wildl. Serv. Tech. Rep. No. 1. 17 pp.

31. Hawkins AS. 1984. The U.S. response. In Flyways, ed. AS Hawkins, RC Hanson, HK Nelson, HM Reeves, pp. 2-9. Washington, DC: US Dep. Interior.

32. Heitmeyer ME, Fredrickson LH. 1981. Do wetland conditions in the Mississippi Delta hardwoods influence mallard recruitment. Trans. N. Am. Wildl. Nat. Res. Conf. 46:44-57

33. Henny CJ, Anderson DR, Pospahala RS. 1972. Aerial surveys of waterfowl production in North America. 1955-71. US Fish Wildl. Serv. Spec. Sci. Rep., Wildl. 160. $48 \mathrm{pp}$.

34. Hestbeck JB. 1994. Survival of Canada geese banded in winter in the Atlantic Flyway. J. Wildl. Manage. 58:748-56

35. Hestbeck JB, Nichols JD, Malecki RA. 1991. Estimates of movement and site fidelity using mark-resight data of wintering Canada Geese. Ecology 72:52333

36. Hickey JJ. 1952. Survival studies of banded birds. US Fish Wildl. Serv. Spec. Sci. Rep., Wildl. 15. 177 pp.

37. Hilborn R. 1992. Can fisheries agencies learn from experience? Fisheries 17:614

38. Hilborn R, Pikitch EK, Francis RC. 1993. Current trends in including risk and uncertainty in stock assessment and 
harvest decisions. Can. J. Fish. Aquat. Sci. 50:874-80

39. Hilborn R, Walters CJ. 1992. Quantitative Fisheries Stock Assessment. New York: Chapman \& Hall. 570 pp.

40. Hochbaum GS, Walters CJ. 1984. Components of hunting mortality in ducks: a management analysis. Can. Wildl. Serv. Occas. Pap. 52.27 pp.

41. Holling CS, ed. 1978. Adaptive Environmental Assessment and Management. New York: Wiley. 363 pp.

42. Iversen GR. 1984. Bayesian statistical inference. Quant. Soc. Sci. Appl. Ser. 07-043. Newbury Park, CA: Sage. 79 pp.

43. Jahn LR, Kabat C. 1984. Origin and role. In Flyways, ed. AS Hawkins, RC Hanson, HK Nelson, HM Reeves, pp. 374-83. Washington, DC: US Dep. Interior

44. Johnson DH, Burnham KP, Nichols JD. 1986. The role of heterogeneity in animal population dynamics. Proc. Int. Biometrics Conf., 13th. 15 pp.

45. Johnson DH, Grier JW. 1988. Determinants of breeding distributions of ducks. Wildl. Monogr. 100. 37 pp.

46. Johnson DH, Nichols JD, Conroy MJ, Cowardin LM. 1988. Some considerations in modeling the mallard life cycle. In Waterfowl in Winter, ed. MW Weller, pp. 9-20. Minneapolis, MN: Univ. Minn. Press

47. Johnson DH, Nichols JD, Schwartz MD. 1992. Population dynamics of breeding waterfowl. In Ecology and Management of Breeding Waterfowl, ed. BDJ Batt, AD Afton, M G Anderson, CD Ankney, DH Johnson, et al, pp. 446-85. Minneapolis, MN: Univ. Minn. Press

48. Deleted in proof.

49. Johnson DH, Sparling DW, Cowardin LM. 1987. A model of the productivity of the mallard duck. Ecol. Model. 38: 257-75

50. Johnson FA, Williams BK, Nichols JD, Hines JD, Kendall WL, et al. 1993. Developing an adaptive management strategy for harvesting waterfowl in North America. Trans. N. Am. Wildl. Nat. Res. Conf. 58:565-83

51. Kaminski RM, Gluesing EA. 1987. Density-and habitat-related recruitment in mallards. J. Wildl. Manage. 51:14148.

52. Koford RR, Sauer JR, Johnson DH, Nichols JD, Samuel MD. 1992. A stochastic population model of mid-continent mallards. In Wildlife 2001: Populations, ed. DR McCullough, RH Barrett, pp. 170-81. New York: Elsevier

53. Lincoln FC. 1930. Calculating water- fowl abundance on the basis of banding returns. USDA Circ. $118.4 \mathrm{pp}$.

54. Lincoln FC. 1935. The waterfowl flyways of North America. USDA Circular 342. $12 \mathrm{pp}$.

55. Lubow B. 1993. Stochastic Dynamic Programming (SDP): User's Guide. Fort Collins, CO: Colo. Coop. Fish \& Wildl. Res. Unit. 119 pp.

56. Lubow B. 1995. SDP: Generalized software for solving stochastic dynamic optimization problems. J. Wildl. Manage. In press

57. Ludwig D, Hilborn R, Walters C. 1993. Uncertainty, resource exploitation, and conservation: lessons from history. Science 260:17,36

58. Martin EM, Carney SM. 1977. Population ecology of the mallard. IV. A review of duck hunting regulations, activity, and success, with special reference to the mallard. US Fish Wildl. Serv. Res. Publ. 130. 137 pp.

59. Martin FW, Pospahala RS, Nichols JD. 1979. Assessment and population management of North American migratory birds. In Environmental Biomonitoring, Assessment, Prediction, and Management-Certain Case Studies and Related Quantitative Issues, ed. J Cairns Jr, GP Patil, WE Walters, pp. 187-239. Fairland, MD: Int. Coop. Publ. House

60. Meanley B. 1982. Waterfowl of the Chesapeake Bay Country. Centreville, MD: Tidewater. $210 \mathrm{pp}$.

61. Miller JR, Hay MJ. 1981. Determinants of hunter participation: duck hunting in the Mississippi Flyway. Am. J. Agric. Econ. 63:677-84

62. Murphy DD, Noon BD. 1991. Coping with uncertainty in wildlife biology. $J$. Wildl. Manage. 55:773-82

63. Nelson HK, Bartonek JC. 1990. History of goose management in North America. Trans. N. Am. Wildl. Nat. Res. Conf. 55:286-92

64. Nichols JD. 1991. Responses of North American duck populations to exploitation. In Bird Population Studies: Their Relevance to Conservation and Management, ed. CM Perrins, J-D Lebreton, G Hirons, pp. 498-525. Oxford, UK: Oxford Univ. Press

65. Nichols JD. 1991. Science, population ecology, and the management of the American black duck. J. Wildl. Manage. 55:790-99

66. Nichols JD. 1991. Extensive monitoring programmes viewed as long-term population studies: the case of North American waterfowl. Ibis 133: Suppl. 1:88-98

67. Nichols JD, Conroy MJ, Anderson DR, 
Burnham KP. 1984. Compensatory mortality in waterfowl populations: a review of the evidence and implications for research and management. Trans. N. Am. Wildl. Nat. Res. Conf. 49:535-54

68. Nichols JD, Johnson FA. 1989. Evaluation and experimentation with duck management strategies. Trans. N. Am. Wildl. Nat. Res. Conf. 54: 566-93

69. Nichols JD, Reinecke $\mathrm{KJ}$, Hines JE. 1983. Factors affecting the distribution of mallards wintering in the Mississippi Alluvial Valley. Auk 100:932-46

70. Oberholser HC. 1917. The great plains waterfowl breeding grounds and their protection. In USDA Yearbook, pp. 197204. Washington, DC: US Govt. Print. Off.

71. Phillips JC, Lincoln FC. 1930. American Waterfowl. Boston, MA: Houghton Mifflin. 312 pp.

72. Pospahala RS, Anderson DR, Henny CJ. 1974. Population ecology of the mallard. II. Breeding habitat conditions, size of the breeding population, and production indices. US Fish Wildl. Serv. Res. Publ. 115. 73 pp.

73. Puterman ML. 1994. Markov Decision Processes: Discrete Stochastic Dynamic Programming. New York: Wiley. 649 pp.

74. Raveling DG, Heitmeyer ME. 1989. Relationships of population size and recruitment of pintails to habitat conditions and harvest. J. Wildl. Manage. 53:1088-1103

75. Reeves HM. 1966. Influence of hunting regulations on wood duck population levels. In Wood Duck Management and Research: A Symposium, ed. JB Trefethen, pp. 163-81. Washington, DC: Wildl. Manage. Inst.

76. Rexstad EA. 1992. Effect of hunting on annual survival of Canada geese in Utah. J. Wildl. Manage. 56:297-305

77. Salyer JC II, Gillett FG. 1964. Federal refuges. In Waterfowl Tomorrow, ed. JP Linduska, pp. 497-508. Washington, DC: US Dept. Interior

78. Schwarz CJ. 1993. Estimating migration rates using ring recoveries. In The Use of Marked Individuals in the Study of Bird Population Dynamics: Models, Methods, and Software, ed. J-D Lebreton, PM North, pp. 255-64. Berlin: Birkhauser Verlag

79. Seber GAF. 1970. Estimating time-specific survival and reporting rates for adult birds from band returns. Biometrika 57:313-18

80. Seber GAF. 1972. Estimating survival rates from bird-band returns. J. Wildl. Manage. 36:405-13

81. Smith GW, Reynolds RE. 1992. Hunting and mallard survival, 1979-88. J. Wildl. Manage. 56:306-16

82. Smith RI, Blohm RJ, Kelly ST, Reynolds RE. 1989. Review of data bases for managing duck harvests. Trans. N. Am. Wildl. Nat. Res. Conf. 54:537-44

83. Sparrowe RD, Patterson JH. 1987. Conclusions and recommendations from studies under stabilized duck hunting regulations: management implications and future directions. Trans. $N$. Am. Wildl. Nat. Res. Conf. 52:320-26

84. Stengel RF. 1994. Optimal Control and Estimation. New York: Dover. 639 pp.

85. Trost R, Dickson K, Zavaleta D. 1993. Harvesting waterfowl on a sustained yield basis: the North American perspective. In Waterfowl and Wetland Conservation in the 1990s-A Global Perspective. Int. Waterfowl and Wetlands Research. Bur. Spec. Pub. 26, ed. M Moser, RC Prentice, J Van Vessem, pp. 106-12. Slimbridge, UK

86. US Department of the Interior. 1988. Supplemental Environmental Impact Statement: Issuance of Annual Regulations Permitting the Sport Hunting of Migratory Birds. Washington, DC: US Fish Wildl. Serv. 340 pp.

87. US Department of the Interior, Environment Canada, and Secretaria de Desarrollo Social Mexico. 1994. 1994 Update to the North American Waterfowl Management Plan. Expanding the Commitment. Washington, DC: US Fish Wildl. Serv. 30 pp.

88. Walters CJ. 1986. Adaptive Management of Renewable Resources. New York: MacMillan. 374 pp.

89. Walters CJ, Hilborn R. 1978. Ecological optimization and adaptive management. Annu. Rev. Ecol. Syst. 9:157-88

90. Walters CJ, Hilborn R, Oguss E, Peterman RM, Stander JM. 1974. Development of a simulation model of mallard duck populations. Can. Wildl. Serv. Occas. Pap. 20. 35 pp.

91. Williams BK. 1982. Optimal stochastic control in natural resource management: framework and examples. Ecol. Model. 16:275-97

92. Williams BK. 1988. MARKOV: a methodology for the solution of infinite time horizon Markov decision processes. Appl. Stochastic Models Data Anal. 4: 253-71

93. Williams BK. 1989. Review of dynamic optimization methods in renewable 
natural resource management. Nat. Res. Model. 3:137-216

94. Williams BK. 1995. Adaptive optimization and the harvest of biological populations. Biometrics. In review

95. Williams BK, Nichols JD. 1990. Mod- eling and the management of migratory birds. Nat. Res. Model. 4:273-311

96. Winkler RL. 1972. Introduction to Bayesian Inference and Decision. New York: Holt, Rinehart, \& Winston. 563 pp. 